\title{
An Analysis of the Information Content of Foreign Exchange Rate Movements
}

\author{
John F. Pinfold \\ Vestec Limited, Auckland, New Zealand \\ Email: j.f.pinfold@xtra.co.nz
}

How to cite this paper: Pinfold, J.F. (2022) An Analysis of the Information Content of Foreign Exchange Rate Movements. Journal of Mathematical Finance, 12, 275-300. https://doi.org/10.4236/jmf.2022.121016

Received: January 24, 2022

Accepted: February 21, 2022

Published: February 24, 2022

Copyright (c) 2022 by author(s) and Scientific Research Publishing Inc. This work is licensed under the Creative Commons Attribution International License (CC BY 4.0).

http://creativecommons.org/licenses/by/4.0/

(c) (i) Open Access

\begin{abstract}
Few of us fail to realize foreign exchange rates are ratios rather than prices, but we almost universally use them as if they were in fact the prices of currencies. This paper converts FX rates into prices by defining the value of each currency as its spending power in its home country: the place where it can be spent. Each FX rate becomes the ratio of two such values. The value of the absolute spending power of one currency in relation to another is not considered. Instead, the changes in the spending power of each currency relative to its counterpart contained in daily FX movements are examined. To make this observable, a synthetic exchange rate series is generated from the ten floating currencies most frequently traded against the US dollar. In this series the change in spending power (value) of each currency each day is known. The spending power changes derived from these synthetic FX rates are compared with the information which can be derived from actual exchange rates. The results show changes in FX rates contain almost no useable information on changes in currency values and are in fact unintuitive and highly misleading. If market participants act on the assumption that, in the absence of price sensitive information, yesterday's FX rate is the best estimate of today's rate, they will trade in a manner that leads to FX volatility rather than mean reversion. A solution to this problem is proposed. All changes in the value of individual currencies can be made completely transparent by introducing a global benchmark currency to replace the US dollar as the vehicle currency in FX trades.
\end{abstract}

\section{Keywords}

Foreign, Exchange, Currency, Purchasing, Power, Value, Vehicle

\section{Introduction}

In finance, risk is generally defined as price volatility which is inextricably linked 
to an inability to predict future prices. The ability to predict future prices allows investors to profit from mispricing. The price of an asset should equal the price of the asset at the end of the period discounted by the appropriate discount rate. If the price of an asset diverges from the expected price at the end of the period, then arbitrage should bring it back into line. A volatile price is therefore a sign of an inability to predict future prices. Foreign exchange rates are notoriously volatile and pose one of the greatest risks faced by many firms.

The FX risk for an individual transaction can be hedged, at a price. Longer term exposures are difficult and expensive to hedge. For example, the exposure of a company's competitiveness to FX changes, and the changes occurring in the value of assets and liabilities denominated in foreign currencies. In addition, the risk reduction available to investors from international diversification is reduced by the foreign exchange risk accompanying this strategy. It is difficult to hedge this risk in a cost-effective manner.

Arguably, the greatest unsolved mystery in finance is why the relative purchasing power of currencies does not play a major role in determining exchange rates. In 1996, Kenneth Rogoff [1] wrote a paper reviewing the extensive research on the subject, calling it the "purchasing power parity puzzle". He described purchasing power parity (PPP) as, "the disarmingly simple empirical proposition that, once converted to a common currency, national price levels should be equal". He, like others who have studied the PPP literature, finds "unequivocal evidence" changes in purchasing power resulting from exchange rate movements are not quickly reversed. Rogoff describes the 15 percent reversal in deviations from PPP which occur in the following year as "glacial".

In this paper I will endeavor to cast light on this problem by taking a novel approach to determining how much information on currency price level changes is contained in exchange rate movements. I will not make any attempt to assess the difference between price levels in different countries at any point in time. Instead, I will analyze the daily changes in currency price levels and determine how much information on these changes can be obtained by analyzing movements in exchange rates. The answer will surprise. Neither the extent of the movement of the underlying value of a particular currency, or indeed the actual direction of such a movement, can be ascertained with any accuracy by analyzing exchange rates. The errors are in fact large enough to largely account for the volatility we find in exchange rates.

To achieve this task, we need to ascertain the change in purchasing power of each currency each day. We have been conditioned to simply look at the exchange rate change and draw our own conclusions. However, just as humankind once thought the earth was flat and the sun revolved around the earth, the way we are conditioned to think can badly mislead us. If we are to test the information content of FX rates, we cannot use them as a starting point and then assume our ideas on the information they contain are correct. We must start with the variable we are trying to determine, that is the absolute purchasing power of a currency. This is something we are unable ascertain directly from exchange rates 
over short time intervals with our current state of knowledge.

The solution is to generate a synthetic exchange rate system where we do know the change in the purchasing power of each currency each day. If it has the same mathematical and statistical relationships as the real exchange rate system, we will be able to see how the information on the changes in purchasing power of each currency translates into changes in exchange rates. This paper will lead you through how such a synthetic exchange rate system can be created and how the underlying movements in the values of individual currencies can enhance or cancel each other out, or indeed how both currencies can move in the opposite direction from the direction naturally assumed from the exchange rate movement itself.

The results are surprising, because we are not taught how the movement of the ratio of two prices is mathematically different from the movement of the two underlying prices from which this ratio is calculated. In addition, we may assume the US dollar can be viewed as the money behind the system due to its role as the vehicle currency in foreign exchange markets.

We have become conditioned to thinking of the US dollar as having a much more special place in the system than it has. Its historical significance gives it the illusion of possessing powers it no longer possesses. Its power was established when it was used to underpin the gold exchange standard, adopted after World War 2 as part of the 1944 Bretton Woods Agreement. Participating countries fixed the value of their currencies against the US dollar and agreed to exchange their currencies on demand for US dollars at the agreed rate. The US fixed its currency against the value of gold, initially at US\$35 per ounce. Central banks holding US dollars could exchange them for gold. This meant the holder of any participating currency had the theoretical ability to exchange their currency for US dollars and then exchange the US dollars for gold. From 1944 until 1971, when US President Richard Nixon ended the international convertibility of US dollars into gold, all the major currencies were in effect fixed against the value of gold. Despite attempts to realign the system by revaluing currencies, by 1973 the system collapsed, and most currencies were allowed to float to levels determined by market forces.

Floating currencies were not adopted because they are a superior system. They are what you end up with when you have no system. Parties simply obtain the currencies they need by swapping the currency they have for the one they want at the best rate of exchange they can obtain. It is essentially a system of barter. That is exactly what we would call it if anything other than currencies were being swapped. It was hardly noticed when the ability to see the international purchasing power of a currency changing directly from its exchange rate disappeared, which happened when the US dollar's value ceased to be fixed to gold. The unit of universal measure now moved in a manner statistically indistinguishable from a random walk [2]. Often, we will simply take the movement in an exchange rate against the dollar as the movement in the value of the currency. When we need to think about it more closely, we adjust this rate up or down to 
compensate for the movement of the value of the US dollar. This, as likely as not, is going to be wrong, as you will discover.

The magnitude of the change which occurred when the fixed exchange rate system was abandoned in favor of floating currencies can be best visualized by using an analogy. When the value of currencies could no longer be calculated in terms of gold via the fixed US dollar exchange rate, it was equivalent to removing a common currency, gold, from the system. There was no longer a unit of fixed value. The operation of the FX markets becomes equivalent to operating a stock market in the absence of money. If this occurred, stocks would need to be swapped one for the other. When no counter party for the desired swap is in the market, it becomes necessary to carry out two or more swaps to obtain the desired the stock. The largest cap stocks would need to act as intermediaries to achieve desired swaps. In this market, there would be no way to tell the price of any stock. Swaps achieved via one intermediate stock may imply a different price for a stock to an equivalent transaction achieved via a different stock. Constantly changing swap ratios will give little clue as to which stock is moving in price, or by how much. It can easily be seen how introducing money as a means of exchange in such a market would allow prices to become apparent and movements in prices easily quantifiable. Indeed, the bartering of stocks is so inefficient it is almost inconceivable that such a market could exist in a world where money exists. Yet that is the how foreign exchange markets operate.

I will shortly show the information which would be available if changes in the purchasing power of currencies were easily obtainable, and how little of that information is obtainable from exchange rates. I will show how deceptive relying on exchange rate information can be. To do this I define the purchasing power of a currency as its purchasing power in its home country, as that is the only place it can be spent. It is unnecessary to quantify the magnitude of that purchasing power as only daily changes will be analyzed. Following this I will introduce the concept of using a global benchmark currency as the vehicle currency for the market and how, if introduced, it would become a universal measure of constant purchasing power.

The approach taken in this paper is a novel one. Almost all research into exchange rates analyses the exchange rates themselves. This paper looks at the level below, that is the movements in the purchasing power of the individual currencies themselves. While these movements in absolute purchasing power are unobservable, their mathematical properties can be derived and the impact of this mathematics on exchange rates can be observed. This opens up new insights into the mathematical properties of exchange rates and allows a fuller understanding of the complexities of dealing with a ratio of two prices where the prices themselves are essentially unobservable.

\section{Key Facts about Foreign Exchange Markets}

Before beginning the analysis, it is worthwhile refreshing our understanding of 
the pertinent aspects of how the foreign exchange markets operate. Foreign exchange markets are essentially a network of bank dealing rooms where dealers stand in the market to buy and sell currencies. There are many currencies, and a huge number of potential currency pairs, so the market uses a vehicle currency, the US dollar, as an intermediary currency for almost all trades. This reduces the number of possible trades to a manageable number as each currency only needs to be traded against the US dollar. There are about 24 currency pairs not involving the US dollar which trade against each other. These are called cross trades. In 2019 these were 12 percent by value of all trades on the foreign exchange markets [3]. These cross trades will be ignored in the analysis which follows because there is no material difference in the price of these currencies when exchanged in a cross trade to their price when doing the equivalent trade using the US dollar as a vehicle currency. They exist because there is a small savings in transaction cost as they only incur one buy-sell spread instead of two. Any difference in price between a cross trade and the equivalent trade done via the US dollar will be small and transitory. Arbitragers will compete for the quick and easy profit resulting from any price discrepancy and drive prices to the point where the difference is uneconomic to exploit.

In 2019, spot trades, that is trades settled on the day, made up only 30 percent of market turnover. Forward contracts made up 14 percent of trades and FX swaps 49 percent [3]. The remaining 7 percent are currency swaps, options, and other products. The domination of FX swaps will be surprising to many readers as they are not well known except by market participants. An FX swap is the simultaneous purchase and sale of identical amounts of one currency for another on two different value dates, one of which is most commonly the current spot rate. Most are used by financial market institutions to fund their foreign exchange balances. For example, a bank buys a currency on behalf of a speculator client. Rather than settling the transaction at the market close, the bank uses an FX swap to delay the need for settlement to the following day, or the following week. FX swaps are priced using the spot exchange rate, to which an adjustment is made for the difference in interest rates between the two currencies. The sale of products other than spot trades does not increase the volatility of prices as they are useful for managing differences in supply and demand over time for individual currencies. If anything, they would reduce exchange rate volatility. Only spot prices at market close are analyzed in this paper.

Foreign exchange markets operate continuously, 24 hours a day during the trading week. In 2019 daily turnover was 6590 billion US dollars [3]. Most turnover is speculative. The annual volume of currency trades for the 10 currencies which will be used to create the synthetic currency series varies from 13 times annual GDP for Mexico to 86 for NZ, with an overall average of 39 [4]. This means most currency trades cannot be driven by purchasing the currency needed for an underlying transaction, or to hedge an underlying exchange rate exposure. Supply and demand are therefore primarily driven by speculation. 
Accordingly, imbalances between supply and demand from trade imbalances and the hedging of actual exposures cannot reasonably be blamed for most price volatility.

\subsection{How Are Future FX Rates Predicted}

The most used method for determining future exchange rates is technical analysis. It is used by 90 percent of FX professionals who weight its importance in decision making at between 30 and 50 percent [5]. This is greater than the two other major categories, fundamental and flow analysis. Technical analysis is a method of predicting price movements and future market trends by studying charts of past market prices and or volumes. While technical analysis is generally disparaged by academics, studies on its effectiveness frequently show it is in fact profitable [5]. Whichever method is used, there is no evidence market participants try to break down the underlying value movements of individual currencies and use this in their decision making. For the daily time frames being considered here, all the methods use exchange rates as if they were prices, that is they take the figures at their face value without delving into the underlying reality.

\subsection{What Determines Exchange Rates?}

The dominant theory on what determines long term exchange rates is purchasing power parity, which holds that exchange rates are determined by relative prices and adjust to accommodate differences in inflation rates between nations. In addition, there is good evidence of a positive relationship between real exchange rates and terms of trade. The productivity growth differential between traded and non-traded goods has also been shown to have a small impact. Capital flows, government consumption and trade restrictions also play a part [6].

However, this paper focuses on short term changes in exchange rates and there is no reason to assume macroeconomic principles create the underlying forces which determine daily changes in the value of exchange rates. As one leading paper put it, "macroeconomics is an inessential piece of the exchange rate volatility puzzle" [7]. Exchange rate models are unable to outperform a random walk at periods out to one year [8].

Over the short term it is microeconomics which prevails. A market transaction occurs at the price where supply meets demand. Demand for a currency increases as its exchange rate drops and supply increases as the exchange rate increases. Empirical evidence on how this creates short term volatility is lacking, but economists have developed models in an attempt to explain this volatility. Models which are capable of explaining the level of short-term volatility cover the complete range. On the one hand there are monetary model theories which find that robust forecasts of economic fundamentals can create differences in forecast future exchange rates large enough to explain observed volatility [8]. At the other extreme are models which find "noise", that is irrational speculation, 
can generate all observed volatility without the need for any effect from macroeconomic aggregates [9]. In aggregate all of this research provides no definitive answers, apart from an agreement the causes of foreign exchange volatility, both short term and long term, are a puzzle.

Blaming short term volatility on noise traders must be questioned. Foreign exchange markets are different to equity and bond markets because currency is not an investment in itself. There is no correct value which can be derived from the future cash flows arising from holding a particular currency, these arise when the currency is invested in other markets. The underlying demand for currency arises from trade transactions and the need for funds for investment in foreign markets. These flows come in a variety of sizes but can be large and lumpy as transactions tend to be irregular and large.

On the second-by-second time frame operating on foreign exchange markets, supply and demand must be highly volatile, creating far more price volatility than the average daily volatility of 0.72 percent found in the data used in this paper. Market makers smooth these mismatches in supply and demand, and this must considerably reduce the exchange rate volatility which would be created by natural ebbs and flows of the underlying transactions. This market making is speculative in nature. While some participants will be "irrational" in their decision making, this will cause them to lose money and they will be driven from the market by the more astute players. Foreign exchange operations generate large profits, and profitable speculation is inconsistent with creating noise, that is random fluctuations in exchange rates. Profits come from buying a currency when it is cheaper than it should be and selling it when it is more expensive than it should be. This competition for profits is the fundamental mechanism which creates market efficiency and drives prices to the point where only the most efficient speculators can survive in the market. If these speculators are absent from the market price volatility must higher. The participant who offers the best price gets the trade, and if speculators are getting most of the trades, they must be offering the best prices to non-speculator participants.

Of course, this view is not shared by many researchers. However, I believe the underlying supply and demand in foreign exchange markets is highly erratic and would create very high volatility if it were not for the smoothing effect created by market makers and speculators. A ready supply of noise traders do enter the market through retail FX trading platforms, but they are just grist for the mill as more experienced players take their money until they either learn the trade or leave penniless. Their effect cannot outweigh the countereffect of the more profitable participants. Creating noise in an efficient market is a loss-making strategy.

The view I have just expressed has the opposite initial assumption to most academic studies. They assume exchange rates in a floating exchange rate should be stable and that something is disturbing this stability. I take the view that supply and demand fluctuations are so great that foreign exchange markets have 
intrinsically high volatility and speculative activity drives down that volatility to the point where the limits of arbitrage prevent any further reduction [10].

\section{How Informative Are Exchange Rate Movements?}

For any two currencies there are four potential combinations of international purchasing power changes which can occur when an exchange rate moves in a specified direction. One of these will be impossible as the combination cannot mathematically result in an exchange rate movement in the direction observed. If the US dollar goes up in value it will cause the exchange rate to drop. If the value of the other currency drops it will cause the exchange rate to drop. Clearly two movements in value which both cause the exchange rate to drop cannot result in an increasing exchange rate. When the exchange rate moves in the opposite direction there are another three possible combinations. These are illustrated in Table 1 using hypothetical changes for the Euro against the US dollar.

Table 1. Possible directions of value changes as an exchange rate changes.

\begin{tabular}{ccc}
\hline \multicolumn{3}{c}{ If exchange rate increases from EUR/USD $=1.2000$ to EUR/USD $=1.5000$} \\
\hline & US dollar value goes up? & US dollar value goes down? \\
\hline Euro value goes up? & $\Uparrow \uparrow$ Possible & $\Downarrow \uparrow$ Possible \\
Euro value goes down? & $\Uparrow \downarrow$ Not Possible & $\Downarrow \downarrow$ Possible \\
\hline If exchange rate decreases from EUR/USD $=1.5000$ to EUR/USD $=1.2000$ \\
\hline
\end{tabular}

Table 1 shows the combinations of currency value movements which can result from an exchange rate going up or going down. The US dollar is represented by $\Uparrow$ and the Euro by $\uparrow$, with the arrow direction representing whether the value of the currency goes up or down. The value of the Euro is the numerator in the ratio represented by the exchange rate and the US dollar the denominator, hence their value changes have opposing mathematical effects on the exchange rate. This means the relative changes in value of the two currencies determines the direction in which the exchange rate moves. Where a combination is deemed to be possible, there is a possible combination of value changes in the two currencies which can result in the exchange rate moving in the specified direction.

The possibility of one or other of the two currencies not moving at least one PIP, the minimum change possible in an FX quote, is ignored as it is fleetingly rare given the minute size of a PIP. If currency movements are independent and random, each possible combination would occur 25 percent of the time. As one combination is impossible, there is a one in three chance of guessing the correct direction of changes in value of the two currencies when only the change in the exchange rate is available. 
We would like to know the size of the value change as well as the direction of the change and this poses just as great a challenge. Table 2 illustrated the problem. To make the direction changes more easily recognizable arrow labels will be used in this paper from now on. The exchange rate movements will be labelled with the bold arrows $\uparrow \downarrow$ and the two currencies involved will be inside brackets labelled with $\Uparrow \Downarrow$ and $\uparrow \downarrow$ arrows. $\Uparrow \Downarrow$ are the up and down movements in the purchasing power (value) of the US dollar which is the quote currency. $\uparrow \downarrow$ are the up and down movements in the underlying value of the base currency, which in this case is the Euro.

Table 2. Relationship between value changes and the direction of value movements.

\begin{tabular}{|c|c|c|c|c|c|}
\hline \multicolumn{6}{|c|}{ Time $=1$ EUR1.2000/USD and Time $=2$ EUR1.5000/USD $=1.5000 \uparrow$} \\
\hline \multicolumn{3}{|c|}{$\uparrow(\Uparrow \uparrow)$} & \multicolumn{3}{|c|}{ 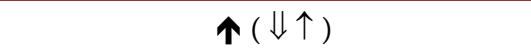 } \\
\hline EUR/USD & $1.2000 \rightarrow 1.5000$ & $+25.0 \%$ & EUR/USD & $1.2000 \rightarrow 1.5000$ & $+25.0 \%$ \\
\hline Value USD & $1.0000 \rightarrow 1.1111$ & $+11.1 \%$ & Value USD & $1.0000 \rightarrow 0.8889$ & $-11.1 \%$ \\
\hline Value EUR & $1.0000 \rightarrow 1.3889$ & $+38.9 \%$ & Value EUR & $1.0000 \rightarrow 1.1111$ & $+11.1 \%$ \\
\hline \multicolumn{3}{|c|}{$\boldsymbol{\uparrow}(\Uparrow \downarrow)$} & \multicolumn{3}{|c|}{$\boldsymbol{\top}(\Downarrow \downarrow)$} \\
\hline EUR/USD & $1.2000 \rightarrow 1.5000$ & $+25.0 \%$ & EUR/USD & $1.2000 \rightarrow 1.5000$ & $+25.0 \%$ \\
\hline Value USD & \multirow{2}{*}{\multicolumn{2}{|c|}{ Not Possible }} & Value USD & $1.0000 \rightarrow 0.7272$ & $-27.3 \%$ \\
\hline Value EUR & & & Value EUR & $1.0000 \rightarrow 0.9090$ & $-9.1 \%$ \\
\hline \multicolumn{6}{|c|}{ Time $=1$ EUR1.5000/USD and Time $=2$ EUR1.2000/USD $=1.5000 \downarrow$} \\
\hline \multicolumn{3}{|c|}{$\boldsymbol{\downarrow}(\Uparrow \uparrow)$} & \multicolumn{3}{|c|}{$\downarrow(\Downarrow \uparrow)$} \\
\hline EUR/USD & $1.5000 \rightarrow 1.2000$ & $-20.0 \%$ & EUR/USD & $1.5000 \rightarrow 1.2000$ & $-20.0 \%$ \\
\hline Value USD & $1.0000 \rightarrow 1.3333$ & $+33.3 \%$ & Value EUR & \multirow{2}{*}{\multicolumn{2}{|c|}{ Not Possible }} \\
\hline Value EUR & $1.0000 \rightarrow 1.1111$ & $+11.1 \%$ & Value USD & & \\
\hline \multicolumn{3}{|c|}{$\downarrow(\Uparrow \downarrow)$} & \multicolumn{3}{|c|}{$\downarrow(\Downarrow \downarrow)$} \\
\hline EUR/USD & $1.5000 \rightarrow 1.2000$ & $-20.0 \%$ & EUR/USD & $1.5000 \rightarrow 1.2000$ & $-20.0 \%$ \\
\hline Value USD & $1.0000 \rightarrow 1.1111$ & $+11.1 \%$ & Value USD & $1.0000 \rightarrow 0.9090$ & $-9.1 \%$ \\
\hline Value EUR & $1.0000 \rightarrow 0.8889$ & $-11.1 \%$ & Value EUR & $1.0000 \rightarrow 0.7272$ & $-27.3 \%$ \\
\hline
\end{tabular}

The value changes are equal to the change in relative value of the exchange rate. The calculations are: Top panel 1.3889/1.1111 = 1.25 (i.e. $+25 \%$ ), $1.1111 / 0.8889=1.25$ and $0.9090 / 0.7272=1.25$. Bottom Panel 1.1111/1.3333 = 0.8 (i.e. $-20 \%), 0.8889 / 1.1111=0.8$ and $0.7272 / 0.9090=0.8$.

In Table 2 the magnitude of the up and down movements in the Euro exchange rates, that is the top panel relative to the bottom panel, are of equivalent size. If one movement is followed by the other, the net change is zero. In some instances, the possible movement combinations which can result in the exchange rate in question are within finite limits, for example in $\uparrow(\Downarrow \uparrow)$ the limits are \pm 25 percent. In others, for example $\downarrow$ ( $\uparrow \uparrow)$ they are only limited by reasonableness. For example, mathematically, the US dollar could have increased by 100 percent and the Euro by 60 percent to produce the 20 percent decrease in the 
exchange rate, but this is unlikely to occur.

The movements in Table 2 are intended to be typical of what might occur over a multi-year period. In both cases we cannot detect the direction of movements in the value of the two currencies, and the range of movements in the value of the Euro are from -9.1 percent to +38.9 percent in the top panel and from -27.3 percent to +11.1 percent in the bottom half of the table. Simultaneously analyzing the exchange rates of multiple exchange rates changes over the same period may allow us to refine our estimates. The possibilities for doing this will be analyzed shortly using a synthetic exchange rate series. However, if the only information we have is the movement of an exchange rate, we have a very limited ability to estimate either the direction in value change of a currency or the extent of that movement.

\section{Creating a Synthetic Exchange Rate Series}

To obtain a series of exchange rates where the movement in international purchasing power of each currency, each day, relative to the currency's purchasing power in its home country, is precisely known, a synthetic currency with the same mathematical and statistical relationships as actual exchange rates was created. It was assumed exchange rates and the underlying changes in currency follow a random walk when analyzed daily, as this is what the literature tells us. Over longer periods, the literature on PPP tells us there is a trend of mean reversion. The daily data is not perfectly normal, it has skewness and kurtosis and its variance changes over time in a seemingly random fashion. To simulate this in a realistic way is problematic, and unnecessary. The statistical properties of a currency are preserved if the data is simply randomly sorted. If each currency is independently sorted on a random basis and recombined, it creates a synthetic currency series with the same statistical characteristics as the original series.

This was done using daily US dollar exchange rates against the ten most frequently traded floating currencies over the period from the start of 1999 to the end of 2021. The series could not extend before 1999 as that was the date of the introduction of the Euro. The ten currencies chosen were the Australian dollar (AUD), the Canadian dollar (CAD), the Swiss franc (CHF), the Euro (EUR), the British pound (GBP), the Norwegian krone (NOK), the New Zealand dollar (NZD), the Mexican peso (MXN), the Japanese yen (JPY), and the Swedish krona (SEK). In 2019 these currencies featured as one of the currency pairs in 85.6 percent of all foreign exchange turnover [3]. The bulk of the excluded currencies are not freely floating and hence do not move randomly in value against the US dollar.

Randomly sorting these currencies breaks the correlation between currency movements. In exchange rates, the value of all currencies is measured against the US dollar, therefore its movement in value creates a correlation between currencies. This correlation must be removed, then reintroduced as a known movement against the US dollar so value changes can be quantified. To create a realistic series of random US dollar values, it was assumed the statistical characteris- 
tics of the Euro and US dollar were the same, so another randomly assorted Euro series became the US dollar series. The Euro is the best candidate for this role as it generates 36.5 percent of all trades with the US dollar.

The volatility of the value changes of the US dollar is not known, but its value creates the correlation between exchange rates. A correlation matrix of the 10 chosen exchange rate series produced an average correlation of 0.44 . The ratio of the proportion of the synthetic US dollar movement to the movement of other currencies was adjusted until the average correlation of the series became 0.44 . As an exchange rate is the ratio of two prices, using the ratio of two exchange rates roughly doubles the volatility of the resulting series compared to actual FX rates. The value changes of each synthetic exchange rate were therefore scaled down to give the same standard deviation as each actual currency. This process changed the average correlation of the series, so the US dollar proportion needed to be repeatedly readjusted, in an iterative process using Excel Solver, until both the average correlation and the volatilities of each of the 10 currencies were correct.

The result is a series of exchange rates for 10 currencies against the US dollar which should behave in the same way as real exchange rates. For this new series, the daily change in value of each currency's international purchasing power in relation to its home purchasing power is exactly known, as is the daily change in value of the US dollar. It is now possible to attempt to extract information from these exchange rates. These estimates can be compared with the known value changes present, to test their accuracy.

\section{Analyzing the Synthetic Exchange Rates}

\subsection{How Do We Estimate Exchange Rate Movements}

If we know the movement in value of the US dollar it is a simple matter to calculate the value movement of the other currency featuring in the exchange rate. The US dollar index is used by market participants for this purpose. The US dollar index is calculated using the methodology specified by the Federal Reserve [11]. It is a trade weighted index, so it measures the impact on the US economy of exchange rate changes. It includes countries with fixed or managed exchange rates and four countries make up 60 percent of the index. For economists interested in the impact of exchange rate changes on US economy it is excellent. For estimating the change in value of the US dollar in an exchange rate it is inherently inaccurate.

Each day, each of the 10 synthetic currencies change in purchasing power, and that value is measured against the changing value of the US dollar. The US dollar has the same value change built into each of the 10 daily FX rates. The change in the exchange rate is the compound return of the value change in the US dollar and the value change of currency in question. If we wish to estimate the change in the US dollar, we have 10 numbers derived by multiplying with a constant, and we need to extract the constant from those numbers. The constant is random and can be positive or negative. If we have enough numbers derived in this 
manner, the random part, that is the movement in the synthetic currencies value, should average out to zero, and the constant should reveal itself as the difference from zero. Thus, the best estimate of the value change of the US dollar is the negative of the unweighted average of the 10 exchange rates.

The accuracy of this estimate was tested against the actual change in value for the synthetic currency series using the 5760 daily prices for each of the 10 synthetic currencies. The direction of movement of the US dollar was wrongly estimated 13.1 percent of the time and the average error in the extent of the movement was 37.3 percent of the actual movement. When the trade weighted US dollar index [12], calculated from the synthetic currency series was used instead of the equal weighted index, the direction of movement was wrongly estimated for 17.1 percent of exchange rates, and the error averaged 53.3 percent of the actual movement, confirming the superiority of the equal weighted index for this purpose.

\subsection{Currency Value Changes Derived from Estimated US Dollar Value Changes}

The next step in the process is to use the information FX market participants can obtain from changes in exchange rates, to make estimates of the movements of the 10 synthetic currencies. The US dollar is the only currency with sufficient information to allow its value change to be estimated from changes in exchange rates. The estimated value change for the other 10 currencies can be easily derived from the estimated value change of the US dollar and the relevant change in exchange rate.

The difference between the estimate in the change in international purchasing power of a currency, and the actual change in this value, will be the error of the estimation. We know the actual change from the value used to construct the exchange rate when the synthetic currencies were created. Part of the estimation error arises directly from the error in estimating the value of the US dollar. This error is compounded by the error created when the direction of movement in value of the currency in question is incorrectly determined. Sometimes this will arise because the direction in movement in value of the US dollar has been miscalculated. In other instances, it will because the error in the extent of the value change in the US dollar results in a change in which of the two currencies appears to have moved the most.

We will begin the analysis by assuming the direction of change of each of the synthetic 10 currencies can be determined from the direction of the change in value of the US dollar. In Table 3 the synthetic currency movements are broken down into the six possible direction combinations. For ease of discussion these are labelled Case A to Case F. Two directions of movement, for two currencies, gives four combinations. However, two of these combinations can give rise to two directions of movement in the exchange rate depending which currency moves in value the most. Case $\mathrm{A}$ and Case $\mathrm{C}$ have the same directions of value movements for the exchange rate and US dollar i.e., $\uparrow(\Downarrow \uparrow) \& \uparrow(\Downarrow \downarrow)$, as do 


\section{Case D and Case F i.e., $\downarrow(\Uparrow \downarrow) \& \downarrow(\Uparrow \uparrow)$.}

Table 3. Averages of the frequency of value change direction combinations of synthetic currencies.

\begin{tabular}{|c|c|c|c|c|c|c|}
\hline & $\begin{array}{c}\text { Case A } \\
\uparrow(\Downarrow \uparrow)\end{array}$ & $\begin{array}{c}\text { Case B } \\
\uparrow(\Uparrow \uparrow)\end{array}$ & $\begin{array}{l}\text { Case C } \\
\boldsymbol{\top}(\Downarrow \downarrow)\end{array}$ & $\begin{array}{c}\text { Case D } \\
\downarrow(\Uparrow \downarrow)\end{array}$ & $\begin{array}{c}\text { Case E } \\
\downarrow(\Downarrow \downarrow)\end{array}$ & $\begin{array}{c}\text { Case F } \\
\boldsymbol{\downarrow}(\Uparrow \uparrow)\end{array}$ \\
\hline Actual frequency & $\begin{array}{c}25.1 \% \\
(24.0-25.7)\end{array}$ & $\begin{array}{c}12.4 \% \\
(9.4-13.9)\end{array}$ & $\begin{array}{c}12.4 \% \\
(9.9-16.5)\end{array}$ & $\begin{array}{c}24.8 \% \\
(24.3-25.6)\end{array}$ & $\begin{array}{c}13.0 \% \\
(9.2-15.6)\end{array}$ & $\begin{array}{c}12.3 \% \\
(9.9-15.2)\end{array}$ \\
\hline Estimated frequency & $\begin{array}{c}24.0 \% \\
(21.7-25.4)\end{array}$ & $\begin{array}{c}11.8 \% \\
(10.5-12.8)\end{array}$ & $\begin{array}{c}14.2 \% \\
(11.3-18.6)\end{array}$ & $\begin{array}{c}24.2 \% \\
(22.2-26.4)\end{array}$ & $\begin{array}{c}12.4 \% \\
(10.3-14.0)\end{array}$ & $\begin{array}{c}12.4 \% \\
(10.3-14.0)\end{array}$ \\
\hline Normal Distribution & $25.0 \%$ & $12.5 \%$ & $12.5 \%$ & $25.0 \%$ & $12.5 \%$ & $12.5 \%$ \\
\hline
\end{tabular}

Note: Exchange rate increase $\uparrow$ decrease $\downarrow$ US dollar value increase $\Uparrow$ decrease $\Downarrow$ Synthetic currency value increase $\uparrow$ decrease $\downarrow$. Frequencies are the percentage of the time an exchange rate has the specified combination of direction movements. Figures in brackets are the highest and lowest frequencies found in the synthetic versions of AUD CAD CHF EUR GBP NOK NZD MXN JPY \& SEK.

If the movements in currency values were distributed with perfectly normality, the frequencies of movement directions would be exactly 25 percent or 12.5 percent, as shown in the bottom row of Table 3. The top row of Table 3 is slightly different due to the skewness of the synthetic exchange rates. Using the estimated value of the US dollar, determined using the equal value index, also results in a small increase in the discrepancy over and above that found when using the actual US dollar value change. The figures in brackets in these tables are the range of values seen across the 10 currencies.

The degree of change in a currency's value will depend on the combination of value movements involved. The effect which different combinations of movement directions have on the extent of the value change can be seen in Table 4. There are differences in the degree of movement depending on the case.

Table 4. Average movement in value of synthetic currencies split into value change directions.

\begin{tabular}{cccccccc}
\hline & Case A & Case B & Case C & Case D & Case E & Case F \\
& $\uparrow(\Downarrow \uparrow)$ & $\uparrow(\Uparrow \uparrow)$ & $\uparrow(\Downarrow \downarrow)$ & $\boldsymbol{\downarrow}(\Uparrow \downarrow)$ & $\downarrow(\Downarrow \downarrow)$ & $\downarrow(\Uparrow \uparrow)$ \\
\hline \multirow{2}{*}{ Actual } & $0.362 \%$ & $0.534 \%$ & $-0.184 \%$ & $-0.357 \%$ & $-0.498 \%$ & $0.181 \%$ \\
& $(0.216-0.496)$ & $(0.334-0.699)$ & $(-0.135--0.221)$ & $(0.225-0.475)$ & $(-0.328--0.613)$ & $(0.140-0.204)$ \\
Estimated & $0.365 \%$ & $0.495 \%$ & -0.200 & $-0.352 \%$ & $-0.489 \%$ & $0.193 \%$ & $(0.169-0.210)$ \\
& $(0.226-0.496)$ & $(0.349-0.614)$ & $(-0.172--0.228)$ & $(-0.229--0.465)$ & $(-0.361--0.565)$ & $(0.17 \%)$ \\
\hline
\end{tabular}

Note: Exchange rate increase $\uparrow$ decrease $\downarrow$ US dollar value increase $\Uparrow$ decrease $\Downarrow$ Synthetic currency value increase $\uparrow$ decrease $\downarrow$. Movements are the daily percentage change in value of the synthetic currencies ( $\uparrow$ or $\downarrow$ ) when compared with their purchasing power in their home country. Figures in brackets are the highest and lowest average value movements found in the synthetic versions of AUD CAD CHF EUR GBP NOK NZD MXN JPY \& SEK.

As the currency values are assigned randomly, the movements should be approximately the same for the four underlying direction combinations. Case A and Case D both have an average change in value of 0.36 percent. Case $\mathrm{B}$ and Case F, when combined, have a similar average value change, as do Case $\mathrm{C}$ and E. Any small differences are due to the non-normality of the exchange rates upon which the currencies are based. Whether an exchange rate combination 
becomes Case B or F, is dependent on whether the movement of the value of the US dollar is greater or less than the value change of the other currency, as this determines whether the exchange rate goes up or down. The same applies to Case C and E. Also, for these cases, if the US dollar moves in value more, the other currency will tend to have a small movement, and vice versa when the US dollar moves less.

Knowing the direction of movement in value of both of the underlying currencies is needed to accurately predict the degree of movement of the currency in question. The exchange rate change and direction of movement of the US dollar alone does not allow Case A with an average return of 0.362 percent to be distinguished from Case $\mathrm{C}$ with an average return of -0.184 percent. Similarly, Case D cannot be distinguished from Case F. This problem is completely independent of any problem arising from the accuracy of the prediction of the direction and extent of the value change in the US dollar.

Table 5. Volatility of synthetic currencies split into value change directions.

\begin{tabular}{|c|c|c|c|c|c|c|}
\hline & $\begin{array}{c}\text { Case A } \\
\boldsymbol{\uparrow}(\Downarrow \uparrow)\end{array}$ & $\begin{array}{c}\text { Case B } \\
\text { 个( }(\uparrow)\end{array}$ & $\begin{array}{l}\text { Case C } \\
\boldsymbol{\uparrow}(\Downarrow \downarrow)\end{array}$ & $\begin{array}{c}\text { Case D } \\
\downarrow(\Uparrow \downarrow)\end{array}$ & $\begin{array}{c}\text { Case E } \\
\downarrow(\Downarrow \downarrow)\end{array}$ & $\begin{array}{c}\text { Case F } \\
\downarrow(\Uparrow \uparrow)\end{array}$ \\
\hline Actual & $\begin{array}{c}0.362 \% \\
(0.224-0.507)\end{array}$ & $\begin{array}{c}0.453 \% \\
(0.234-0.674)\end{array}$ & $\begin{array}{c}0.166 \% \\
(0.126-0.202)\end{array}$ & $\begin{array}{c}0.387 \% \\
(0.236-0.778)\end{array}$ & $\begin{array}{c}0.360 \% \\
(0.229-0.467)\end{array}$ & $\begin{array}{c}0.161 \% \\
(0.126-0.182)\end{array}$ \\
\hline Estimated & $\begin{array}{c}0.390 \% \\
(0.221-0.534)\end{array}$ & $\begin{array}{c}0.333 \% \\
(0.217-0.424)\end{array}$ & $\begin{array}{c}0.172 \% \\
(0.145-0.198)\end{array}$ & $\begin{array}{c}0.337 \% \\
(0.222-0.424)\end{array}$ & $\begin{array}{c}0.389 \% \\
(0.252-1.015)\end{array}$ & $\begin{array}{c}0.168 \% \\
(0.144-0.188)\end{array}$ \\
\hline
\end{tabular}

Note: Exchange rate increase $\uparrow$ decrease $\downarrow$ US dollar value increase $\Uparrow$ decrease $\Downarrow$ Synthetic currency value increase $\uparrow$ decrease $\downarrow$. Volatilities are the standard deviation of the daily percentage change in value of the synthetic currencies ( $\uparrow$ or $\downarrow$ ) where value is defined as the currencies purchasing power in its home country. Figures in brackets are the highest and lowest average volatilities found in the synthetic versions of AUD CAD CHF EUR GBP NOK NZD MXN JPY \& SEK.

Table 5 shows the problems of estimating the degree of movement in value of our 10 synthetic currencies is mirrored in any attempt to estimate price volatility. Price volatility here is defined as the standard deviation of daily value changes, expressed as a percentage of the previous day's value. The average volatility in the actual value change of the US dollar is 0.455 percent and it averages 0.515 percent for other 10 currencies. The volatility of the estimated US dollar value change is slightly different at 0.485 percent.

It is clearly noticeable when looking at Table 5, that the weighted average of the volatilities must be much less than 0.515 percent. This is because splitting them into cases creates groupings with similar values changes, as can be seen in Table 4 . This groups similar value changes together resulting in the cases all having lower volatility than the volatility of each currency when it is not divided into groups.

\subsection{The Accuracy of Individual Daily Value Change Estimates}

The estimates shown in Tables 3-5 are useful to demonstrate the underlying biases created in such estimates by different combinations of value changes. But they are overall averages. As errors average out over time, they are of little 
use in providing guidance to a market participant on the accuracy of such information relating to an individual trade. Over the entire 22-year period analyzed, the geometric average daily return varied from -1.4 to 0.7 PIPs for the 10 currencies. A PIP, or percentage in point, is the smallest movement a currency can make. Buy-sell spreads are normally between 1 and 5 PIPs. The expected underlying long-term trend in daily value movement for any of the currencies, of one or two PIPs, is for practical purposes zero. This means the expected response to a movement in value, in the absence of any price sensitive information, over the long term, is for the previous period's change in exchange rate to be reversed.

Knowing that changes in exchange rate reverse over the long term is not helpful for short term trading unless the short-term value changes are transparent. Here we are interested in how accurate the information on value changes is over the time period of one day. Can a trader use this information to profitably trade currencies knowing long-term exchange rate changes average out to essentially zero? The ability to profitably use information is inextricably tied to its accuracy.

For example, if an FX trader adopts a strategy of buying and selling on the assumption a currency will return to the same exchange rate it traded at a day ago, how much error would there be in the estimate of the value change? We could alternatively ask, "if yesterday's value change in a currency was reversed in an attempt to reverse this value change, how much error would there be in such an assumption"?

To answer questions like these we need to make an estimate of the value movement in each of the 57,590 individual value changes in our synthetic currency series and compare these with the correct value. Case B and Case D can be individually identified, so their value change can simply be calculated using the estimated value change for the US dollar for the day in question. As we cannot distinguish between Cases $\mathrm{A}$ and $\mathrm{C}$ from the exchange rate and value change of the US dollar, it would be possible to assume both are Case A or both are Case C. As Table 3 shows, Case A is twice as common as Case C. It is therefore logical to assume the Case $\mathrm{C}$ value of the currency changes by the Case A estimate, as this will lead to the lowest expected error. In reality this is the error minimization strategy because the higher the weighting of Case C's value in any composite estimate, the greater the overall error. A similar strategy applies to Cases D and F. Assuming both cases change in value by the Case $\mathrm{D}$ estimate minimizes overall estimation error. Overall, this is equivalent to a rule saying to reverse yesterday's changes in value, simply reverse yesterday's exchange rate, after adjusting for the estimated movement in the US dollar.

Table 6 shows the errors found by comparing the best estimate of the movement in the value of a currency with the actual movement built into the synthetic currency when it was created. The inverse of the average movements in the 10 synthetic exchange rates is assumed to be the value change in the US dollar. The change in value of the other currencies is calculated from the exchange rate 
change and the value change of the US dollar.

Table 6. The average error when estimating the value change of synthetic currencies.

\begin{tabular}{|c|c|c|c|c|c|c|c|}
\hline & $\begin{array}{c}\text { Case A } \\
\uparrow(\Downarrow \uparrow)\end{array}$ & $\begin{array}{c}\text { Case B } \\
\uparrow(\Uparrow \uparrow)\end{array}$ & $\begin{array}{l}\text { Case C } \\
\boldsymbol{\uparrow}(\Downarrow \downarrow)\end{array}$ & $\begin{array}{l}\text { Case D } \\
\downarrow(\Uparrow \downarrow)\end{array}$ & $\begin{array}{c}\text { Case E } \\
\downarrow(\Downarrow \downarrow)\end{array}$ & $\begin{array}{c}\text { Case } F \\
\downarrow(\Uparrow \uparrow)\end{array}$ & $\begin{array}{l}\text { Mixed } \\
\text { Cases }\end{array}$ \\
\hline Average value change & $0.362 \%$ & $0.534 \%$ & $0.184 \%$ & $0.357 \%$ & $0.498 \%$ & $0.181 \%$ & $0.260 \%$ \\
\hline \multirow{2}{*}{ Average error } & $0.106 \%$ & $0.104 \%$ & $0.449 \%$ & $0.104 \%$ & $0.101 \%$ & $0.440 \%$ & $0.157 \%$ \\
\hline & \multicolumn{7}{|c|}{$(0.096-0114)(0.099-0.108)(0.367-0.524)(0.097-0.110)(0.095-0.105)(0.362-0.483)(0.146-0.164)$} \\
\hline $\begin{array}{c}\text { Average percentage } \\
\text { error }\end{array}$ & $29.3 \%$ & $19.5 \%$ & $244.0 \%$ & $29.2 \%$ & $20.3 \%$ & $242.6 \%$ & $60.3 \%$ \\
\hline Error standard deviation & $0.133 \%$ & $0.134 \%$ & $0.326 \%$ & $0.130 \%$ & $0.133 \%$ & $0.318 \%$ & $0.193 \%$ \\
\hline Weighting of case type & $19.2 \%$ & $8.6 \%$ & $10.1 \%$ & $19.1 \%$ & $9.2 \%$ & $9.7 \%$ & $24.2 \%$ \\
\hline \multicolumn{4}{|c|}{ Overall average estimation error for the 10 synthetic currencies } & \multicolumn{4}{|c|}{ Average $51.0 \%$ Stdev. of error $27.8 \%$} \\
\hline
\end{tabular}

Note: Exchange rate increase $\uparrow$ decrease $\downarrow$ US dollar value increase $\Uparrow$ decrease $\Downarrow$ Synthetic currency value increase $\uparrow$ decrease $\downarrow$. Average value change is the average of the actual value changes. The error is the difference between the daily estimated value change of the synthetic currencies ( $\uparrow$ or $\downarrow$ ) and the actual value change contained in the exchange rate. The average error is the error as a percentage of the daily value change in the currency. The average percentage error is the error as a percentage of the value change. Error standard deviation is the standard deviation of the average error. Mixed cases are ones where the case assumed in the estimation is different from the true case due to estimation error. Figures in brackets are the highest and lowest average errors found in the synthetic versions of AUD CAD CHF EUR GBP NOK NZD MXN JPY \& SEK.

In Table 6 the results have been assigned to one of two groups. Exchange rates have been assigned Cases from $\mathrm{A}$ to $\mathrm{F}$ if the estimated movement direction determined by a market participant using the information available to them from exchange rate changes would be the ones arrived at by knowing the correct value movements in the US dollar. This is done for Cases $\mathrm{C}$ and $\mathrm{F}$ even though they cannot be distinguished from Cases $\mathrm{A}$ and $\mathrm{C}$ using the exchange rate and estimated value change of the US dollar. Where the case assignment made is different from the case assignment which would have been made if the correct information for the US dollar was available, these have been lumped into the "mixed cases" category. This misassignment has two causes. Firstly, the estimated direction of change in value of the US dollar may not be correct. This happens in 13.1 percent of the estimates. Secondly, in some instances the error in the extent of the change in value of the US dollar has resulted in a change in the movement direction of the exchange rate, that is Case B become Case F, or Case $\mathrm{C}$ becomes Case E. These misassignments occur 24.2 percent of the time. Sometimes they increase the error in the estimate of value change and sometimes they decrease it.

Table 6 shows the extent of the error is dramatically different for different Cases. It is greatest for Cases $\mathrm{C}$ and $\mathrm{D}$, because these will be misclassified as Cases $\mathrm{A}$ and $\mathrm{E}$. Their direction of value change is wrong, and added to that error, the extent of the movement was assumed to be double the correct value because of the way they were classified. The erroneously misclassified cases, that is those labelled mixed cases, are also larger than average. Such misclassification inevita- 
bly results in incorrect values being used when calculating the extent of the currency's movement using the assumed movement in the value of the US dollar.

Positive and negative errors largely cancel one another out over time and across currencies. The daily average overall error for the 22 -year period was 0.0002 percent. The error is on average 51.0 percent of the actual change in value of the currency. The standard deviation of the error is 0.278 percent, but any conclusions based on standard deviation must be treated with caution because the data is not normally distributed.

If we believe yesterday's exchange rate should be the same as todays, assuming the value of the US dollar appears unchanged, we are unlikely to be correct. For Cases B and E, the best-case scenario, we will on average be wrong by about 20 percent of the daily movement in value of the currency in question. At worst we will on average be wrong by just over 240 percent, as occurs in estimates for Cases $\mathrm{C}$ and $\mathrm{F}$.

\subsection{The Effect of Estimation Error on Price Discovery}

Exchange rates evolve on a trade-by-trade basis and there are often many trades per second. Every time a trade changes an exchange rate, the value of one or both the currencies exchanged changes. In most trades the US dollar is only being used as a vehicle currency and these trades require no knowledge of the value of the US dollar as its value is of no direct interest to the two parties trading. Also, the volumes on the buy and sell side seldom match, so a single trade of one currency can be matched against multiple trades by the counterparties. Supply and demand respond to changes in exchange rates as each party strives for the most favorable exchange ratio. Most participants have no interest in determining the value changes of the two currencies in the trade, they are only interested in the ratio of the two values. When analyzed on trade-by-trade basis, the direction of change in the value of the US dollar will constantly switch, and this switching will be built into longer term ups and downs which may occur many times over a day's trading. Estimates of value changes in other currencies will be even more volatile as demand for one currency comes from all other currencies, so currencies each fluctuate independently of one another.

That is not to say there are not times when exchange rate sensitive news arrives in the market. Changes in official interest rates, balance of payments announcements, inflation rates and many other economic fundamentals move exchange rates, sometimes dramatically. However, such information is rapidly incorporated into exchange rates, and only a small percentage of FX changes occur when new information is being assimilated by markets. The rest of the time FX rates are still highly volatile with changes in currency values rivalling those occurring when the markets respond to news.

The information in Tables 3-6 is just a daily snapshot in time. Most market participants will not be using a daily horizon for their trading decisions, and even if they do, they will be focusing on a different time in the 24-hour cycle of 
trades. If the trading rules assumed in Table 6 were being applied by all market participants, the differing time frames they would use would result in different assumptions on the changes in values of currencies and conflicting decisions. On top of this is the sheer inaccuracy of the estimates themselves. These factors on their own would be enough to render attempts to mean revert a currency as nothing different to betting on the outcome of a random process.

There is also the additional problem of errors being systematically wrong, which compounds these difficulties. Figure 1 is a plot of the change in value of the synthetic currencies against the error in the estimate of the change in value.

The white line in Figure 1 is the regression trend line. The estimates as a whole are biased because of the cluster of data running in the direction of the top left to the bottom right, which results from the Case $\mathrm{C}$ and $\mathrm{F}$ value change estimates. They have an average error of about 240 percent, as well as having an incorrect assessment of the direction of the value change.

The error in the estimates does not average out to zero. The slope coefficient of the regression line is 0.8151 , whereas it would be 1.0 if the estimate was unbiased. If one of the synthetic currencies actually moves upward in value by 1.00 percent, the estimate will be that it moves 1.23 percent. If the value movement is -1.00 percent, the estimate is that it will have moved -1.23 percent. However, we know the estimate should equal the actual value movement.

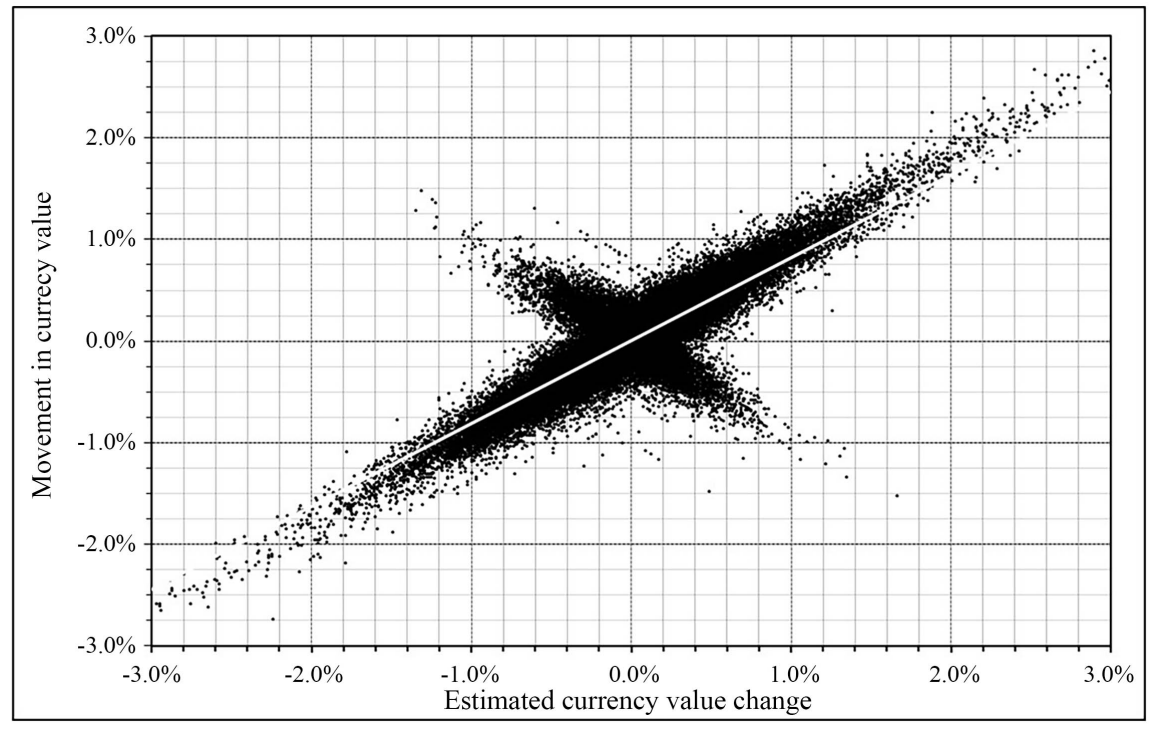

Figure 1. Scatter plot of relationship between the change in currency value and estimation error.

If a market participant were to bet on an exchange rate movement reversing, and their estimate gives a positive change for the previous day, they would short the currency and close out the trade when the currency had reversed the previous days estimated value change. In reality they would have overshot the correct exchange rate for the mean reversion to be complete. If the value change had been negative, they would hold a long position in the currency and hold 
their position after the value change had actually reversed. We know the long run movement in value is zero, so the market participant would unknowingly be trying to end up with a long position in an overvalued currency, or a short position in an undervalued currency. Both are loss making positions. No matter what percentage of market participants sought to drive the process of mean reversion by their investment decisions, they would be unable to drive the exchange rate to a zero daily value change because their strategy is actually creating a force for systematic under and overvaluation resulting from the nature of the error in their estimations. As each currency moves independently of the others some will be being driven to an overvaluation and some to an undervaluation at any given time. These errors all affect the estimated value of the US dollar which feeds directly back into the estimated values of the other currencies, propagating the error creation process.

It is not possible to definitively say how much effect trading to achieve mean reversion would have on volatility, especially as it is a losing strategy. Those adopting it would be driven from the market as they continually lose money or abandon the strategy. The most logical conclusion is that markets do not mean revert in the short term because attempting to adopt such a strategy loses money and currency traders do not continue to carry out loss making strategies once they are proven to be loss making.

The result is an exchange rate regime where the underlying value of currencies has no effect on exchange rates in the short term. In the long term fundamental economic forces will come into play through supply and demand, as well as trading decisions being influenced by the reasonableness of the currencies value given the economic fundamentals. Major economic news may offer an opportunity for such adjustments to be made because market participants will believe the exchange rate will be driven in a certain direction and trade accordingly. Technical analysis techniques may assist in stabilizing currency values as many of their trading rules, such as support levels, moving averages and reversal patterns have the potential to capture information on value changes.

\section{Introducing a Global Benchmark Currency as the Vehicle Currency}

Where there is a problem, a solution should be sought. If an exchange rate regime has an inherent fault, the solution lies in changing or modifying the exchange rate system to remove the fault. There have been proposals to solve exchange rate volatility such as returning to the gold standard, which is impractical for many reasons. A better approach is to identify the root cause of the fault in the system and remove this cause.

Foreign exchange markets need to be converted from a venue where currencies are valued using ratios measured against the constantly changing value of the US dollar. There is a measure of constant value which can be used as a bench- 
mark. That benchmark is the value of a currency measured against its spending power in its home country. Inflation is regularly monitored and reported so changes in this value can be accurately quantified. If every currency is bought and sold at a price measured in terms of a benchmark of the domestic spending power of its home currency, these prices can be readily used to determine the comparative value of the currencies, in other words their exchange rate.

The only way in which such a pricing system for currencies can be established is to use such a benchmark as the reference price for all currencies when quoting prices on the foreign exchange markets. It is unnecessary to value currencies comparative spending power against other currencies to establish this system. Only the changes in spending power of a currency against its home market's spending power are needed to establish changes in the comparative underlying international spending power of currencies. The exchange rate of a currency pair will change by the (geometric) sum of the value changes of the two currencies against the benchmarks.

This currency system could be enacted by deciding on a starting date for the introduction of this system, which we will call a global benchmark currency. From this date onwards, all buy and sell quotes on the foreign exchange markets would be required to be made in terms of the global benchmark currency. On the starting date all currencies would need to be assigned a value in terms of the global benchmark currency. This could simply be based on the last trade price against the US dollar before the new system comes into force. The US dollar would be valued at one unit of the global currency and every other currency would have the same value in global currency terms as it had in US dollar terms at the changeover point. From this point on, each currency would be valued against the benchmark of its purchasing power on the introduction date, and its relative value against another currency would be its change against its benchmark compared with the other currency's change against its benchmark. No attempt would be made to establish purchasing power parity at the establishment date, although purchasing power relative to benchmarks could be established if this was desired for other purposes.

From this point on, currencies would be priced in terms of the purchasing power of their home currency. The two stages of exchanging currencies via the global benchmark currency will produce two price changes. These will be the two changes in purchasing power relative to the two home currencies. When combined these give a single value or exchange rate, which is the relative purchasing power of the currencies. Units of the global benchmark currency come into existence as one currency is sold and ceases to exist when the other side of the transaction is completed. The ability of the global benchmark currency to maintain a stable value may be enhanced if long or short positions in the global benchmark currency were required to be settled at the end of trade each day, using any other currency. This would ensure supply always equals demand.

If speculators are allowed to accumulate large open positions in the global 
benchmark currency this could result in an imbalance between the amounts of other currencies bought and sold over a period of time, which would distort currency prices. This could be particularly troublesome in periods of expected currency volatility, as the global benchmark currency would be a haven against volatility. The flight of money to such a haven would increase instability in the other currencies and could cause the benchmark to drift in value relative to constant purchasing power. Such a drift in value would not destroy its usefulness as a vehicle currency providing the change was gradual over time and did not have significant short-term volatility.

If the value of the global benchmark relative to constant purchasing power changed over time due to market forces, the direction and extent of any comparative change between each and every currency will still be readily determinable at all times, and this is all the information the market needs for pricing decisions. If one was able to devise a market force which would systematically change the value of the global benchmark currency, say be having it increase on average by 10 percent against all currencies, it would be easy to adjust for this in decision making, and it would have no effect on the exchange rate between currencies, as the value of the vehicle currency is a cancelled out when calculating exchange rates not involving the vehicle currency.

An important question to consider is whether a satisfactory market for the global benchmark currency could be established if cross trades were allowed between the other currencies. If cross trades are allowed the US dollar can still be used as a vehicle currency. A 1980 paper by Paul Krugman [13] modelled the process of how vehicle currencies compete, and how one comes to dominate. His model is not definitive about whether or not market forces would cause the global benchmark currency to supplant the US dollar as the dominant vehicle currency if they were allowed to freely compete. Ideally, cross trades should be allowed, but only if they do not interfere with pricing of the global currency. Little would be gained if the global currency mirrored movements in the purchasing power of the US dollar. If the market created two different values for an exchange rate depending on the vehicle chosen, arbitrage would drive the two prices together. If the US dollar won the battle, the global benchmark currency would serve no useful purpose.

One of the essentials for establishing a currency is to force people to use it. Graeber in his book Debt the First 5000 Years [14] explains how early issuers of coins needed to force people to pay taxes using these coins in order to establish them as money. He also points out currencies have been used as a means of account for centuries after the currencies themselves have gone out of circulation. This means the global benchmark currency does not need to be in circulation for it to be used as a measure of value. If the foreign exchange markets use the global benchmark currency as a vehicle currency it will exist and it will become the measure of value. Using it as a measure of value in other financial contracts will not interfere with the setting of an exchange rate between two curren- 
cies. If such contracts are regulated so they cannot be settled in the global benchmark currency it will merely make the contribution of each currency to changes in settlement price transparent. It will allow the splitting of the FX risk between the parties, so that each bears the consequence of a devaluation of their own currency but is unaffected by changes in the counterparty's currency value.

At this point an illustrative example of how a global benchmark currency will work in practice will be helpful for those who are struggling with the concept. Assume the global benchmark currency (GBC) was introduced sometime in the past and the US dollar, was worth $1.000 \mathrm{GBC}$ at the introduction date when it was benchmarked but has since increased in value. The exchange rate at the beginning of the time period is USD1.1023/GBC. The other currencies have moved in value as well, but we don't need to know their benchmark values. We are trying to determine the changes in value of the British Pound, Euro and Australian dollar over an unspecified period between time $=1$ and time $=2$. Table 7 shows the exchange rates of the USD, GBP, EUR and AUD against the GBC at the beginning and end of the period and the changes in value these represent. A good estimate of the change in value of the currencies can be made by simple mental arithmetic without the need to see the actual calculation.

Table 7. Example calculations using the global benchmark currency.

\begin{tabular}{|c|c|}
\hline \multicolumn{2}{|c|}{ Exchange rates measured against global benchmark currency } \\
\hline Time $=1$ & Time $=2$ \\
\hline $\mathrm{USD} / \mathrm{GBC}=1.1023$ & $\mathrm{USD} / \mathrm{GBC}=1.0502$ \\
\hline $\mathrm{GBP} / \mathrm{GBC}=1.3667$ & $\mathrm{GBP} / \mathrm{GBC}=1.4102$ \\
\hline $\mathrm{EUR} / \mathrm{GBC}=1.1431$ & $\mathrm{EUR} / \mathrm{GBC}=1.1316$ \\
\hline $\mathrm{AUD} / \mathrm{GBC}=0.7214$ & $\mathrm{AUD} / \mathrm{GBC}=0.7321$ \\
\hline \multicolumn{2}{|c|}{ Changes in currency value calculated from global benchmark currency exchange rates } \\
\hline value change $=\frac{\Delta \mathrm{USD}}{\mathrm{GBC}}=$ & {$\left[\frac{1.0500}{1.1000}-1\right] \times \frac{100}{1}=-4.73 \%$} \\
\hline value change $=\frac{\Delta \mathrm{GBP}}{\mathrm{GBC}}=$ & {$\left[\frac{1.4102}{1.3667}-1\right] \times \frac{100}{1}=3.18 \%$} \\
\hline value change $=\frac{\Delta \mathrm{EUR}}{\mathrm{GBC}}=$ & {$\left[\frac{1.1316}{1.1431}-1\right] \times \frac{100}{1}=-1.01 \%$} \\
\hline value change $=\frac{\Delta \mathrm{AUD}}{\mathrm{GBC}}=$ & {$\left[\frac{0.7321}{0.72140}-1\right] \times \frac{100}{1}=1.36 \%$} \\
\hline
\end{tabular}

Table 8 shows the same exchange rates using the US dollar as the quote currency. In these exchange rates there is no way to intuitively estimate the movement of the US dollar without comparing it against an index, and accepting the error involved. On the face of it, when quoted against the US dollar, the GBP, EUR and AUD appear to have increased substantially in value, when in fact the 
Euro has decreased in value.

Table 8. Example calculations using the US dollar as vehicle currency.

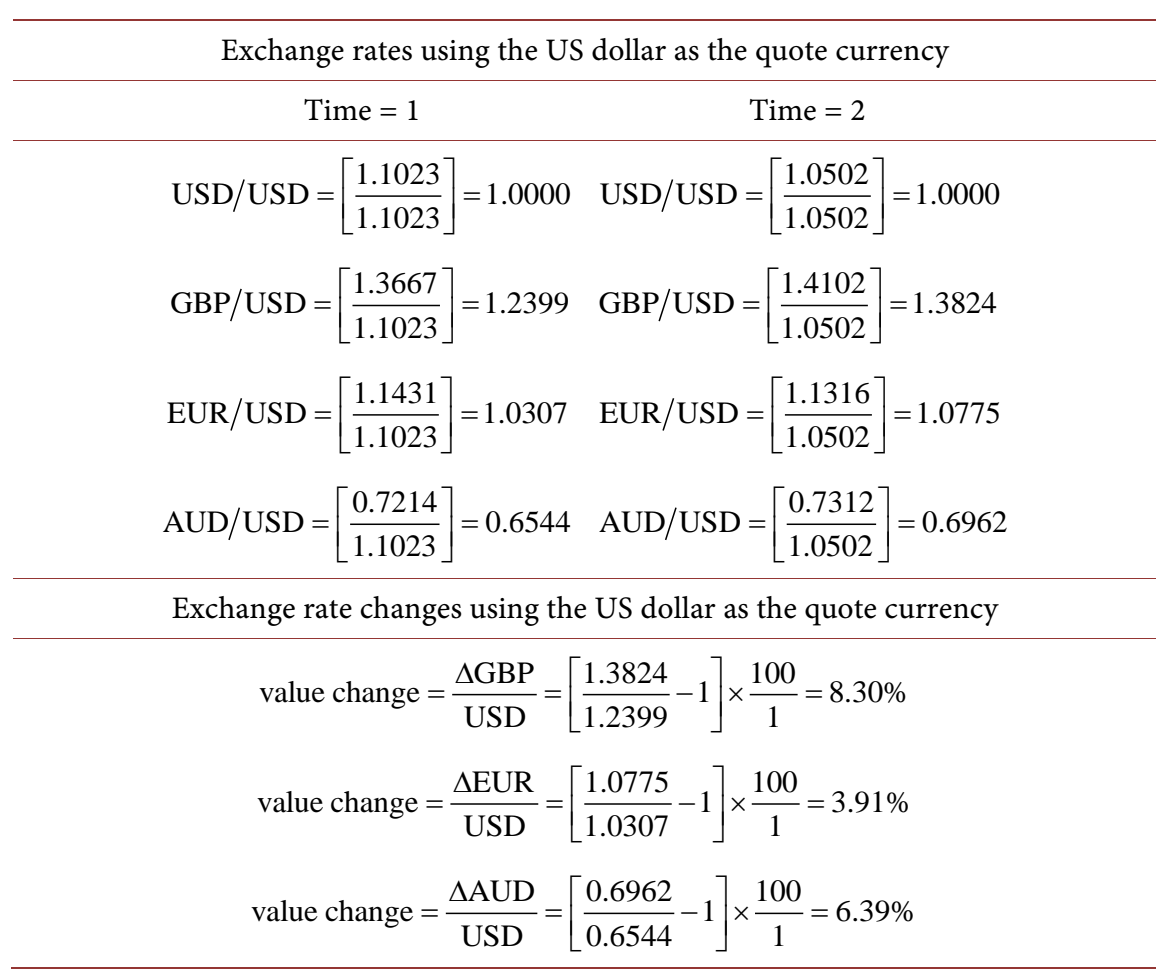

When the exchange rates are quoted against the global benchmark currency, the exchange rates instantly reveal which have gone up in value and which have gone down. Knowing the percentage change in value of each currency allows the relative change between any two pairs to be easily calculated with 100 percent accuracy. When economically significant news arrives in the market, its effect can be correctly allocated to the currency or currencies affected. If currencies trading in the market have a propensity to mean revert, participants can more accurately speculate on this phenomenon and thereby increase market efficiency.

The risks associated with the introduction of a global benchmark currency are small in comparison with many other economic policy decisions. The adjustments needed by the market to incorporate the new currency are not large, and the risks are low. If it does not work, it is simple to revert back to the current system at any time. On the other hand, the benefits of lower currency volatility could be large. If the market's actions lead to an accurate underlying reversal process for exchange rates, the removal of the errors in the process should lead to substantial reductions in volatility. It also opens the way for the market to value currencies on economic fundamentals without the random walk created by misconceptions of value dominating the pricing process.

\section{Limitations and Further Research}

There is a major limitation on the conclusions which can be drawn from this re- 
search. It assumes exchange rate movements are random and that the correlation between exchange rates is entirely due to movements in the value of the US dollar. While no other relationships have been identified in the literature for daily time intervals, that does not mean they do not exist. Indeed, it would be reasonable to assume there are such relationships given the predominance of technical trading rules used by currency traders. If such rules are widely used by traders, the very trading activities of those traders might create relationships between currencies by coordinating the buying and selling activities of participants to create self-fulfilling prophecies; for example, creating support levels for currency pairs. The results presented would be weakened to the extent that the random sorting of exchange rates broke such relationships. In addition, the assumption the statistical characteristics of the US dollar and Euro are the same, used when creating the synthetic currencies, potentially reduces the accuracy of the results.

Despite such limitations, deriving individual currencies' underlying value changes from the estimated value change in the US dollar opens up many opportunities for further research. For example, exploring purchasing power parity relationships using estimated currency value changes rather than exchange rates could prove fruitful. Indeed, any research done on exchange rates in the past may reveal new insights if repeated using estimated currency value changes rather than exchange rates.

\section{Conclusions}

The high volatility of floating exchange rates and the long-term instability in purchasing power parities are one of the most serious problems encountered in international economics, creating unpredictability in the profitability and viability of international trade, as well as substantially increasing the risks associated with international investment. This paper hypothesizes that a major cause of exchange rate volatility, especially over short time frames, is the inability to accurately ascertain changes in the actual value of currencies when exchange rates change.

The fact that exchange rates are an extremely poor representation of relative changes in the international purchasing power of currencies has been demonstrated. Not only are they inaccurate, but they frequently send systematically incorrect pricing signals which misrepresent the direction in which currency values have moved. At the same time, they can substantially overestimate the magnitude of such movements. The present system of using a benchmark with constantly moving value, the US dollar, as a vehicle currency is the root cause of the problem.

A purpose-built currency can replace the US dollar as the intermediary. As its only function in the FX markets would be to act as a vehicle currency, its value should remain constant. This will enable changes in the absolute purchasing power of a currency to replace relative purchasing power changes as the central 
pricing information available to market participants.

While there is no guarantee that the introduction of a global benchmark currency will reduce short term currency volatility and stabilize long term deviations from purchasing power parities, the case made for doing so must be compelling enough to rate serious consideration. This is particularly so because the downside of introducing this system is modest in comparison with the potential benefits.

That is not to say such an innovation would be welcomed by market participants as there are a vast army of people and firms who earn their livings either, directly or indirectly, from the price volatility of foreign exchange markets. Gaining acceptance for an idea like the global benchmark currency from the network of financial institutions making up the global foreign exchange markets may be an uphill struggle, irrespective of its merits.

The FX markets are a great casino, and casinos thrive when the losses and gains are large. If volatility drops and pricing is transparent, skill may no longer give the professional FX speculator an edge over the less knowledgeable players. Economic efficiency comes at a price and that price often entails job losses.

At the very least the subject must be worthy of debate. The need for a better currency system is manifestly obvious, and solutions will only be found by innovation. The solution presented here may not be achievable, but there must be a better way, and it will not be found unless a goal is set and concerted effort is made to progress in that direction.

\section{Conflicts of Interest}

The author declares no conflicts of interest regarding the publication of this paper.

\section{References}

[1] Rogoff, K. (1996) The Purchasing Power Parity Puzzle. Journal of Economic Literature, 34, 647-668.

[2] Diebold, X.F., Gardeazabal, J. and Yilmaz, K. (1994) On Cointegration and Exchange Rate Dynamics. Journal of Finance, 49, 727-735.

https://doi.org/10.1111/j.1540-6261.1994.tb05160.x

[3] Bank of International Settlements (2019) Triennial Central Bank Survey: Foreign Exchange Turnover in April 2019. Monetary and Economic Department, Bank for International Settlements, Basel. https://www.bis.org/statistics/rpfx19.htm

[4] https://data.worldbank.org

[5] Menkhoff, L. and Taylor, M. P. (2007) The Obstinate Passion of Foreign Exchange Professionals: Technical Analysis. Journal of Economic Literature, 45, 936-972. https://doi.org/10.1257/jel.45.4.936

[6] Ricci, L.A., Milesi-Ferretti, G.M. and Lee, J. (2013) Real Exchange Rates and Fundamentals: A Cross Country Perspective. Journal of Money, Credit and Banking, 45, 845-865. https://doi.org/10.1111/jmcb.12027

[7] Flood, R.P. and Rose, A.K. (1999) Understanding Exchange Rate Volatility without the Contrivance of Macroeconomics. The Economic Journal, 109, 660-672. 
https://doi.org/10.1111/1468-0297.00478

[8] Meese, R.A. and Rogoff, K. (1983) Empirical Exchange Rate Models of the Seventies: Do They Fit out of Sample. Journal of International Economics, 14, 3-24. https://doi.org/10.1016/0022-1996(83)90017-X

[9] Devereux, M.B., and Engel, C. (2002) Exchange Rate Pass-through, Exchange Rate Volatility, and Exchange Rate Disconnect. Journal of Monetary Economics, 49, 913-940. https://doi.org/10.1016/S0304-3932(02)00130-7

[10] Shleifer, A. and Vishny, R.W. (1997) The Limits of Arbitrage. The Journal of Finance, 52, 33-55. https://doi.org/10.1111/j.1540-6261.1997.tb03807.x

[11] US Federal Reserve (2019) Revisions to the Federal Reserve Dollar Indexes. https://www.federalreserve.gov/econres/notes/feds-notes/revisions-to-the-federal-re serve-dollar-indexes-20190115.htm https://doi.org/10.17016/2573-2129.48

[12] ICE Futures (2015) U.S. Dollar Index Contracts.

[13] Krugman, P. (1980) Vehicle Currencies and the Structure of International Exchange. Journal of Money, Credit and Banking, 12, 513-526. https://doi.org/10.2307/1991725

[14] Graeber, D. (2014) Debt: The First 5,000 Years. Melville House, London. 